\title{
COMPARISON OF ACADEMIC PERFORMANCE AMONG DIFFERENT HANDED MEDICAL STUDENTS: A CROSS-SECTIONAL STUDY
}

\author{
Umema Zafar ${ }^{\prime \otimes}$, Junaid Ahsan, ${ }^{1,2}$, Romana Ayub', \\ Aruba Zafar ${ }^{1,3}$
}

ABSTRACT

OBJECTIVE: To compare academic performances among different handed second professional medical students in Khyber Medical College, Peshawar, Pakistan.

METHODS: This is a cross sectional study conducted from May to September 2017. A total of 194 medical students from second professional MBBS of any gender were recruited in this study after taking their informed consent. A questionnaire was distributed among the students; their handedness and first professional marks were noted. SPSS v.20.0 was used to analyze the data. Descriptive statistics were applied for both categorical and numerical variables while for comparison independent sample t-test was applied.

RESULTS: Out of 194 students enrolled, 184 (94.8\%) were right-handed \& $10(5.2 \%)$ were left-handed. There were 108 (55.7\%) male \& $86(44.3 \%)$ female students. In right-handed students, 103 (56\%) were males and 81 (44\%) were females while in left-handed students, five $(50 \%)$ were males and five $(50 \%)$ were females. Mean marks in first professional examinations by right-handed and left-handed students were $429.57 \pm 39.054$ and $439.80 \pm 34.1$ I 3 respectively $(p$-value $=0.48 \mathrm{I})$. Mean first professional marks of male and female students were $422.48 \pm 37.53$ and $439.66 \pm 38.46$ respectively $(p$-value $=0.002)$

CONCLUSION: Our study findings infer that handedness does not affect the academic scores in medical students.

KEY WORDS: Academics (Non-MeSH); Handedness (MeSH); Students, Medical (MeSH); Performance (MeSH); Education, Medical, Undergraduate (MeSH).

THIS ARTICLE MAY BE CITED AS: Zafar U Ahsan J, Ayub R, Zafar A. Comparison of academic performance among different handed medical students: a cross-sectional study. Khyber Med Univ J 2020;12(I):49-52. DOI: 10.35845/ kmuj.2020.18789.

\section{INTRODUCTION}

W hat resemblance more perfect than that between our two hands! And yet what a striking inequality there is!" by Robert Hertz"' Handedness has been the subject of debate ever since ancient times. Left-handedness has, even up till now, been discouraged and condemned by some. ${ }^{2}$ In the $15^{\text {th }}$ and $16^{\text {th }}$ century left-handed women were considered witches and were often executed on the pyre. ${ }^{3}$ Whether lefthandedness is a blessing or a curse is more of a personal opinion based on experience. If we look at the meaning of the word right it relates to dexterity, emotional and intellectual soundness, physical strength and good judgement. I Whereas, in old English "left" meant weak, foolish and sinister. ${ }^{4}$

The left and right parts of the brain control the motor functions of the
I. Khyber Medical College, Peshawar, Pakistan.

2. Gajju Khan Medical College, Swabi, Pakistan.

3. Postgraduate trainee, Al-Shifa Trust Eye Hospital, Rawalpindi, Pakistan

Email凶:umema.com@gmail.com

Date Submitted: April 06, 2019

Date Revised: January 18,2020

Date Accepted: January 28, 2020

opposite side of the body. This is called cerebral lateralization. For majority of the people left brain hemisphere controls muscles of speech and hand. Speech and gesture are linked hence the brain has evolved to keep the two together. ${ }^{5}$ Some scientists deny the anatomical basis of asymmetry in the two limbs and attribute it to external influences. This according to them is so because our early ancestors the apes and other animals were ambidextrous.' Another school of thought is that handedness is genetic, developmental as well as cultural. ${ }^{6}$ Genetic and developmental as it can be inherited from parents and developed further during fetal life. As far as inheritance is concerned left-handed fathers are more likely to pass on this trait to their sons, whereas, for left-handed mother there is equal probability of passing it on to her daughters or sons. ${ }^{7}$ The society can also effect handedness, parents sometimes force their left-handed kids to adopt right-handedness by coercion. ${ }^{8}$ This can lead to poor academic performance. According to Cheyne et al, inconsistency in the writing hand and the dominant hand can result in poor performance in academics. ${ }^{9}$

Having left-handed individuals in a family may have its advantages. Research suggests that having close left-handed relatives may result in better memory of the related right-handed people. So according to Christman "The key difference is not whether you are right handed, but whether you are strongly or weakly handed," according to him ambidextrous children and adults are less intelligent than purely left- or righthanded. ${ }^{10}$ In Britain 13\% men and $11 \%$ women are left-handed now as compared to $3 \%$ in 1910 . This shows 
TABLE I: COMPARISON OF ACADEMIC PERFORMANCE BASED ON HANDEDNESS AND GENDER $(\mathrm{N}=194)$

\begin{tabular}{|c|c|c|c|c|c|}
\hline \multicolumn{2}{|c|}{ Variable } & \multirow{2}{*}{$\begin{array}{c}\text { Frequency } \\
\text { (n) }\end{array}$} & \multirow{2}{*}{$\begin{array}{c}\begin{array}{c}\text { First Professional } \\
\text { Marks (Mean } \pm \text { SD) }\end{array} \\
429.57 \pm 39.054 \\
\end{array}$} & \multirow{3}{*}{$\begin{array}{c}\mathbf{t} \\
-0.811\end{array}$} & \multirow{3}{*}{\begin{tabular}{|l} 
P-Value \\
0.481
\end{tabular}} \\
\hline \multirow{2}{*}{ Handedness } & Right & & & & \\
\hline & Left & 10 & $439.80 \pm 34.113$ & & \\
\hline \multirow{2}{*}{ Gender } & Male & 108 & $422.48 \pm 37.53$ & \multirow{2}{*}{-3.13} & \multirow{2}{*}{0.002} \\
\hline & Female & 86 & $439.66 \pm 38.46$ & & \\
\hline
\end{tabular}

evolution favors left-handed, so it must have more merits than demerits. 10 Another study conducted in Sharjah shows the prevalence of left-handed to be $10 \%$. $^{11,12}$

Education levels above bachelors require many skills including inquisitiveness, critical thinking and problem solving skills. These skills are better developed in those with left brain hemisphere dominant. Hence, the right brainers are at a disadvantage when it comes to academic, as they have more of creative and artistic abilities. ${ }^{13}$ In a study conducted in 50,000 Iranian university students it was shown that left-handed students are better in academic performance than their righthanded counter parts. ${ }^{7}$

A widespread idea exists that lefthanded individuals are more intelligent and artistic than the right-handed. However, right-handed are at an advantage in this right-sided world. Advantage such as right-handed chairs for examination, the left-handed have difficulty with those. ${ }^{14}$ A study showed that the mean score attained on examination by left-handed was significantly higher than that of righthanded in all study areas $(p<0.002){ }^{7}$

Left-handedness has always been linked with extremism be it being a genius like Einstein or an insane criminal. ${ }^{15}$ All the good things are done with the right hand like greeting people, eating, writing and the military salute. Whereas, all the taboo things like cleaning the anus and nose are done with the left hand. This distinction is present even in religion such as Islam. Muslim (2020) narrated from Ibn 'Umar (may Allaah be pleased with him) that the Messenger of Allah (peace and blessings of Allah be upon him) said: "No one among you should eat with his left hand or drink with it, for the shaytaan eats with his left hand and drinks with it." 16

The rationale of this study is to find out whether any handedness in an individual has better academic performance in comparison to the other handed individual and if a disparity is seen in any case then which hand is at advantage and what ways and means could be developed to promote the learners with weak academic performance.

\section{METHODS}

This cross-sectional study was conducted in Khyber Medical College, Peshawar, Pakistan over a period of 5 months from May to September 2017. One hundred and ninety four (194) medical students of either gender from second professional MBBS course were included in this study after taking informed consent. The age of the subjects ranged from $|8-2|$ years. The dependent variable was first professional examination marks while the independent variable was handedness.

Using a pre-designed questionnaire the students were asked for their dominant hand based on questions like: with which hand do you write, eat and drink? Which hand do you use to clean the nose and the anus? First professional marks were recorded from each student. The data was entered in SPSS version 20.0. Descriptive statistics were determined for both the variables while Independent sample t-test was applied to compare the academic performance among different handed students for significant difference where $\alpha$ was taken as $\leq 0.05$.

\section{RESULTS}

Out of 194 students enrolled, I84
(94.8\%) were right-handed \& 10 (5.2\%) were left-handed. There were $108(55.7 \%)$ male \& 86 (44.3\%) female students. In right-handed students, 103 (56\%) were males and 81 (44\%) were females while in left-handed students, five $(50 \%)$ were males and five $(50 \%)$ were females. Mean marks in first professional examinations by right-handed and left-handed students were $429.57 \pm 39.054$ and $439.80 \pm 34$. II 3 respectively ( $p$ Value $=0.48 \mathrm{I})$. On gender-based comparison, mean first professional marks of female students were higher as compared to male students (Table l).

\section{DISCUSSION}

There was no significant difference between handedness and academic performance based on scores in first professional exam. Sala, et al. ${ }^{17}$ reported that, hand preference does affect a person's overall cognitive ability. He described the Annett's right-shift theory according to which the right-handed are at a cognitive advantage. He then described another research by Benbow according to which left-handed are at an advantage when it comes to mathematics and those too are mostly males. This probably is due to link of math with spatial ability, which is better in left-handed. ${ }^{17}$

On the basis of intelligence quotient some studies say that left-handed are better than the right-handed individuals. This attribute to the more creative and artistic abilities of left-handed. ${ }^{7}$ The Creative Industries Policy and Evidence Centre (PEC), at Nesta funded by the UK's Arts and Humanities Research Council, reported that creativity and inquisitiveness are the top traits that will be required for excelling in the future job market. ${ }^{18}$ At present however, both left and right brainers are at an equal advantage. ${ }^{19-21}$

The results of this study show that about $5.1 \%$ of the students were left handed. This percentage is less than that seen worldwide but close to the left-handed prevalence seen in India, which is about $5.4 \%{ }^{22}$ The present study further revealed that the average marks of lefthanded students were higher than the right-handed ones but this difference 
was not significant statistically. Therefore, the left-handed did well but it could have been due to chance or the fact that their ratio is not comparable to the right-handed students. This means whether a student is right- or lefthanded, he has equal chances of getting good grades and excelling academically. A study showed that brain dominance has no role in academic performance of students. ${ }^{19}$ Another study conducted on primary school children showed that hardly any difference exists between academic performance and handedness. ${ }^{20}$ A systematic review of 36 studies performed by Eleni Ntolka on 66,108 individuals showed that overall no significant difference exists between right and left-handed individuals $\mathrm{IQ}$ wise. $^{21}$

Comparing of marks by gender, our study showed a significant difference in academic scores by both genders with female students having significantly better result than males. A study conducted on handedness in Nigeria had gender and handedness as parameters of interest and revealed that both had no influence on success in exams. ${ }^{8}$ Another study conducted by Keat showed that gender has no influence whatsoever, on academic success however, what mattered was the learning style preferences of the students. ${ }^{19}$ Ntolka E et al. showed no gender-based differences in IQ level. ${ }^{21}$ More in-depth and larger studies are needed to explore the phenomenon of gender-based differences in marks achieved by medical students.

\section{CONCLUSION}

It can be concluded that handedness has no influence on academic performance while gender affects the academic performance showing females have significantly better scores than males. Hence, whether left or right-handed both can show comparable excellence in academics. More studies with a bigger sample size are needed to further explore this finding.

\section{REFERENCES}

I. Hertz R. The pre-eminence of the right hand. A study in religious polarity. J Ethnogr Theory 20 15;4.

2. History of Handedness. 2012 [Accessed on: April 01, 2019]. Available from URL: http://www. rightleftrightwrong.com/history.ht $\mathrm{ml}$.

3. Mastin L. History of Handedness Recent History [Internet]. Right left right wrong? 2012 [Accessed on: April 0I, 2019]. Available from URL: http:// www.rightleftrightwrong. com/history_recent.html.

4. Left. Dictionary.com. 2017 [Accessed on: April 0I, 2019]. Available from URL: http://www. dictionary.com/browse/left.

5. Forrester G. How children's brains develop to make them right or left handed. 2016 [Accessed on: April 0I, 2019]. Available from URL: http://the conversation.com/howchildrens-brains-develop-to-makethem-right-or-left-handed-55272

6. Llaurens V, Raymond M, Faurie C. Why are some people left-handed? An evolutionary perspective. Philos Trans R Soc Lond B Biol Sci 2009;364:88I-94.

7. Noroozian M, Lotfi J, Gassemzadeh $\mathrm{H}$, Emami H, Mehrabi Y. Academic Achievement and Learning Abilities in Left-Handers: Guilt Or Gift? Cortex 2002;38:779-85.

8. Omede J, Ejigbo MA, Adeniyi GS. Writing Handedness and Academic Achievement of Students of Kogi State College of Education (Kscoe), Ankpa , Nigeria: A Comparative Analysis of School Results. J Educ Policy Entrep Res 20 I 5;2:3 I-42.

9. Cheyne CP, Roberts N, Crow T], Leask SJ, García-Fiñana M. The effect of handedness on academic ability: A multivariate linear mixed model approach. Laterality Asymmetries Body. Brain Cogn 2010 Jul I; I5:45 I-64. DOI: org/I0. 1080/I 3576500902976956.

10. Research Into Left-Handedness And Its Effects. 2017 [Accessed on: April 0I, 2019]. Available from URL: http://www. anythingleft handed.co.uk/research/lefthandedresearch.html.

II. Ackholm Y. Relationship Between Handedness and Academic Performance in Primary School. Asrar 2008.

12. Scharoun SM, Bryden PJ. Hand preference, performance abilities, and hand selection in children. Front Psychol 2014;5:82. DOI: 10.3389/ fpsyg.2014.00082.

13. Vijayan V, Panchu P, Bahuleyan B. Handedness and learning styles : a study of its inter relationship. Int J Res Med Sci 20 I 7;5(I I):5340-6.

14. Suyu-tattao L, Campus A, City T. Lived experiences of left handed students in a right handed academic world. Int J Adv Res Manag Soc Sci 2016;5:426-33.

I5. Stirrups R. Thinking laterally. Lancet 2017;16:113. DOI: org/10.1016/ SI474-4422(I6)30390-8.

16. Islam Question and Answer. 2017 [Accessed on: April 0I, 2019]. p. 3-6. Available from URL: https:// islamqa. info/en/82I 20.

17. Sala G, Signorelli M, Barsuola G, Bolognese M, Gobet F. The Relationship between Handedness and Mathematics Is Non- linear and Is Moderated by Gender , Age , and Type of Task. Front Psychol 2017; 8:948.

18. Easton, Eliza. Is creativity the key to the job market of the future? British Council. 2019 [Accessed on: April 0I, 2019]. Available from URL: https:// www.britishcouncil.org/ anyone-anywhere/explore/digitalcreativity/job-market-future.

19. Keat T, Kumar V, Rushdi M, Nazri N, Xuan L. The Relationship between Brain Dominance and Academic Performance: A Cross-sectional Study. Br J Med Med Res 2016;13: I-9.

20. Faurie C, Vianey-Liaud N, Raymond M. Do left-handed children have advantages regarding school performance and leadership skills? Laterality 2006; I I:57-70. 
2I. Ntolka E, Pastou MP. Right-handers have negligibly higher IQ scores than left-handers: Systematic review and meta-analyses. Neurosci Biobehav Rev 2018;
84:376-93.

22. Ferrari M. Cognitive performance and left-handedness: Comparative analyses in adults with seizures, physical, psychological and learning disorders in a rehabilitation setting. J Rehabil 2007;73:47-54.

\section{AUTHORS' CONTRIBUTIONS}

Following authors have made substantial contributions to the manuscript as under:

UZ: Conception and study design, analysis and interpretation of data, drafting the manuscript, critical review, final approval of the version to be published

JA: Analysis and interpretation of data, drafting the manuscript, final approval of the version to be published

RA: Conception and study design, critical review, final approval of the version to be published

AZ: Analysis and interpretation of data, drafting the manuscript, final approval of the version to be published

Authors agree to be accountable for all aspects of the work in ensuring that questions related to the accuracy or integrity of any part of the work are appropriately investigated and resolved.

CONFLICT OF INTEREST
Authors declared no conflict of interest
GRANT SUPPORT AND FINANCIAL DISCLOSURE
NIL

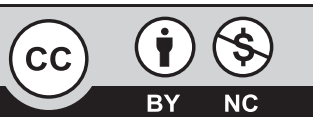

This is an Open Access article distributed under the terms of the Creative Commons Attribution-Non Commercial 2.0 Generic License.

KMUJ web address: www.kmuj.kmu.edu.pk

Email address: kmuj@kmu.edu.pk 